\title{
Open Innovation Practices in Strategic Partnerships of Cloud Computing Providers
}

\author{
Ana Clara Cândido ${ }^{1 *}$, Cristina Sousa ${ }^{2}$
}

\begin{abstract}
The open innovation states that companies can and must use the available resources outside their boundaries. This combination of ideas aligned to the internal and external technologies are crucial to reach a leadership position. The present study aims to identify the practices of open innovation along the partnerships between providers of Cloud Computing. Social Network Analysis were used in the research. Data was collected through questionnaires secondary sources. The companies were asked to identify their strategic partnerships and to identify and characterize the practices of Open Innovation they actually use. Of the 26 strategic partnerships mentioned, only 11 were characterized as practices of the Open Innovation.
\end{abstract}

Keywords: Innovation Management; Open Innovation; Collaboration; Cloud Computing Providers.

Submitted: June $1^{\text {st }} 2017$ / Approved: July $10^{\text {th }} 2017$

\section{Introduction}

Even though the Open Innovation concept is relatively recent, Chesbrough $(2003 ; 2007)$ draw up this theory from several concepts developed in the 1980s and 1990s, namely the concept of complementary assets (Teece, 1986). The main idea is that the success of an innovation strategy not only depends on the innovation capacity, being strongly determined by a set of infrastructures and capabilities enabling the commercialization success and the diffusion of the innovation on the market. However, the innovator does not always control these complementary assets, being necessary to form partnerships with other organizations (Rothaermel, 2001).

The Open Innovation literature increasingly refers to the analysis of the collaborative processes of companies (Lee et al., 2010; Enkel \& Gassman, 2007) evidencing the approach of the themes of collaboration networks in the context of the open model. The authors consider the existence of collaboration as a synonym for the adoption of Open Innovation models. But will it always be like this?

This study aims to contribute to tackle three gaps identified in the extant literature: 1) The need for studies addressing the adoption of the open model in information technology firms; 2) The existence of few studies on adoption of Open Innovation practices in small and medium enterprises (SMEs); 3) The shortage of studies in the context of follower countries (countries outside the technological frontier). Therefore, this study empirically assesses the use of Open Innovation Practices in strategic partnerships of small and medium cloud computing providers located in a technological park in Brazil. The following research questions were raised: Which are the Open Innovation practices adopted by companies in development and diffusion of services based on cloud computing? Are partnerships established by these cloud providers in fact Open Innovation practices?

\section{From Closed Innovation to Open Innovation}

The recognition of the role of different sources of knowledge and innovation, within and outside firms, is not recent (von Hippel, 1986). For example, Napolitano (1989) states that companies may innovate from own (internal) resources (e.g. internal R\&D, process and product engineering and contribution of collaborators) and external resources (technology acquisition, raw materials and intermediate products, relationships with customers and suppliers, observation of competitors, interaction with universities, search of patents and scientific publications databases, etc.).

The literature also refers the necessity of matching these different sources (internal and external) of knowledge and innovation, as outlined by the absorptive capacity literature (Cohen \& Levinthal, 1989; 1990). For them, the innovation strategy success is associated with the capacity to recognize the value of the new knowledge, and to assimilate and commercial apply it. Thus, one of the main merits of the Chesbrough's Open Innovation concept is to highlight the increasing firms' acceptance of the innovation strategies based on this "openness", as well as the development of an analytical framework, enabling to relate and to integrate important concepts to the innovation management literature that were previously dispersed. Gassmann, Enkel and Chesbrough (2010, p. 215) note the diversity of the areas in which this theme is gaining momentum: "Today, open innovation has changed its status from the research interest of a few to a mainstream research area. Initiated by scholars in the field technology and innovation management, it is currently often also cited in strategy, general management and organization behavior journals".

The open innovation model contrasts with the closed innovation model, in which competitive advantages are directly related to the existence of sophisticated R\&D laboratories and high investments in

(1) Federal University of Santa Catarina (UFSC), Department of Information Science (CIN),

Florianópolis - SC, Brazil - Interdisciplinary Centre of Social Science (CICS.NOVA)

(2) Univ Portucalense, Research on Economics, Management and Information Technologies - REMIT \& Instituto Universitário de Lisboa (ISCTE-IUL), DINAMIA'CET-IUL

*Corresponding author: ana.candido@ufsc.br 
infrastructures and activities. This was the common way to reach new discoveries and to get leading positions in the market (Chesbrough, 2003; 2004; Gann, 2004; Smith, 2004; Hemphill, 2005; Blau, 2007).

Meanwhile, throughout the last decades, several unsuccessful business cases of firms with strong R\&D capacity have been exposed. From the current comprehension on innovation management practices, it is possible to list some misconceptions of the innovation process carried out by managers over the years. An example is the case of the Xerox Corporation and its Palo Alto Research Center (PARC) that has a robust internal R\&D structure. For many of the valuable innovations developed there, the company did not identify a commercial application. This lack of use of innovations generated internally is avoided in the open innovation model, because they could have been employed as a strategic asset and commercialized (Chesbrough, 2003). The experience of Procter \& Gamble demonstrates this fruitful situation: the ideas generated in their laboratories, which are not applied internally, are put on hold during three years, and, if after this period, they are not being employed internally they will be sold to other firms

\section{Networks and Open Innovation Management}

The Open Innovation model is based on the idea that the creation of large internal R\&D centers is an obsolete strategy, being the combination of both internal and external knowledge sources vital for the success of the innovation endeavor (Chesbrough, 2003). The company needs to define which internal resources are used and which external interactions will be developed using collaborations, alliances, spinoffs or licensing. This is particularly the case of SMEs, due to the complexity of the innovation process (Zeng, Xie \& Tam, 2010).

The growing openness of corporate innovation strategies reflects on the increased formation of alliances and networks. In the Open Innovation process, partners can be other firms (customers, suppliers, competitors), research organizations (universities and research centers) or public entities. According to Chiaroni, Chiesa and Frattini (2010) empirical evidence suggests that the implementation of the open model depends on the establishment of inter-organizational networks with the presence of several types of actor: universities, research institutes, suppliers, customers, etc.

In a recent analysis focused on 137 manufacturing SMEs located in China, Zeng, Xie and Tam (2010) explore the various innovation networks, and their relationship with the firms' innovation performance. Their results show a positive correlation between the cooperation with other enterprises, with research organizations and with intermediary institutions, and the performance of SMEs. However, cooperation with government agencies does not appear to have a significant impact on the innovation performance of SMEs.

Moreover, Laursen and Salter (2006) identify two important variables in the process of composition of the networks: i) the magnitude of the demand to integrate actors, determined by the number of channels used by the company; and ii) the depth of search for potential partners to form a network, determined by the formation of a diverse network of actors. These variables are crucial for the formation of networks and consequently assist in the adoption of the Open Innovation model by companies, recognizing the absorption of knowledge as a driving motivation for collaborative work.

In this context of increasing networking, the design and implementation of innovation strategies raise new challenges related to the choice of partner's, and the setting goals for partnership and ownership of their results. Vanhaverbeke et al. (2012) systematized these challenges in the following rules:

1. The selection of the right or more appropriate partners is crucial, because the Open Innovation requires the sharing of risks, time and investment, making important a clear and even division of duties and benefits.

2. The company that proposed the joint development - central company - usually manages the network, in order to ensure the harmony of interaction.

3. The survival of the partnership is conditioned to the partners' motivation. It is claimed that the firms' innovation network needs to be constantly maintained active. Therefore, it is important to maintain the partners' enthusiasm and instigate new challenges.

4. Network management (Rule 2) also implies that the central company discerns partners who are not acting according to what had been agreed. Those that are not complying with the rules previously established must leave the network.

5. The openness in communication and in reporting among network partners, associated with the trust factor, is central to the success of the partnership.

6. Manage the balance between the company's internal management and the external management of the network.

7. The interaction between the partners becomes easier to manage if they have similar goals, ambitions and size. SMEs often fear to interact with large firms and this fact often hinders trust between partners.

8. The Open Innovation management also involves controlling costs. In an innovation network, the various partners may be working in a specific task. The central firm has to keep the overall cost under control.

9. Document and record every activity of the project are also tasks for the firm responsible for managing the network. Over time, the central firm will have a deeper understanding of the competencies of each partner that can facilitate the management of that network or of other future networks.

10. Lastly, manage tensions and problems proactively. Open communication and follow-up meetings can avoid such situations. 
Therefore, these challenges point to the need to organize the interaction with the external environment and strengthening collaboration network management capabilities. The identification of key partners for the projects is an important competence of the company, as well as having the maturity to partnership with external stakeholders and managing the collaborative process. The continuous evaluation of the network may change future business strategies, namely directing efforts to the processes where the firm has expertise and knowledge, and getting out partnerships cease to be strategic (Dittrich \& Duysters, 2007).

Such collaborative environment has also influenced the public financing policies of several countries, favoring programs for collaborative projects between universities and companies, as well as agreements between countries. As mentioned by Valk, Chappin and Gijsbers (2011, p. 25) “(...) in a recent Policy Brief of the OECD, the potential for innovation depends on how well knowledge circulates and how well the system is connected: policies to foster or enable the development of world class clusters and networks are thus of growing importance".

\section{Methodological Procedures}

\section{Sample}

The sample consists of nine firms, all of related to the cloud computing vertical of Santa Catarina's Association of Technology Companies (ACATE) in Brazil. Most of the interviewed firms operate with provide services Software as a Service (SaaS) and have a small size with a fairly low number of employees (under 20 employees in most of the firms).

For confidentiality reasons, the name of firms interviewed are not disclosed in this paper, thereby numbers are used to identify the firms (Firm 1, Firm 2, Firm 3 and so on). The name of the partners mentioned throughout the interviews will be revealed in the cases where the interviewed firms allowed their disclosure; in the other cases partners are identified by type and by a letter (for example, client company A).

\section{Methods}

The empirical study is based on two methods: Social Network Analysis and Content Analysis. The following paragraphs describe this approach in detail.

A network is composed of nodes (actors) and ties (relations). In this analysis, the nodes are the interviewed companies and their partner organizations in the innovation process. Therefore, we are analyzing inter-organizational networks. A tie exists when one of the interviewed firms establishes a partnership for innovation purposes.

The Social Network Analysis (SNA) is the use of a set of measures that allow characterizing the interaction patterns (network morphology) and its actors (properties of ties) (Sousa, 2008). According to Valk, Chaplin and Gijsbers (2011, p. 26) "literature in the area of social network analysis (SNA) gives insight into concepts of network structure that may influence for instance the extent of diffusion of knowledge through a network".
The choice of SNA is justified by the broad vision that it provides to the identification of the relations and partnerships between stakeholders of the innovation process, in this case, cloud computing providers and their partners: universities, suppliers, customers, research centers, etc. Furthermore, the SNA allows verifying patterns and observations about the cloud computing development in a Brazilian technological center, making possible to have an overview of the partnerships of the interviewed firms.

In order to (re)construct the networks, adjacency matrices were build, reflecting the innovation partnerships identified through interviews or secondary sources. Three different networks are (re)constructed and analyzed:

1. The overall network of all partnerships of all interviewed firms (Figure 1): provides an overview of the collaborative networks of the firms interviewed, reflecting strategic partnerships mentioned at interview (primary source) and the strategic partnerships identified though secondary sources (website of the interviewed firms; reports in the media; ACATE website; websites of research institutions and government agencies related to science, technology and innovation). 59 partnerships were identified and analyzed.

2. The network of strategic partnerships (Figure 2): using only the data collected through the interviews and reflecting the set of partnership considered strategic by the firms. 26 strategic partnerships were identified and analyzed.

3. Network of strategic partnerships that involved open innovation practices (Figure 3): built after a content analysis of the interviews, mapping only the strategic partnerships that actually involve Open Innovation practices. 9 strategic partnerships involving open innovation practices were identified and analyzed

The networks were then analyzed and graphed using UCINET and NetDraw softwares. In this study, the SNA was conducted at two steps:

1. Network diagrams using the Netdraw software. In these diagrams, the actors are represented by squares and the ties are represented by arrows. In these arrows the analyzed company (ego) is the source and the partner (mentioned in the interview or in a secondary source) is the target. The strength of each tie is represented by the thickness of the line. A tie is considered strong when the partnership is mentioned by both actors, thus involving reciprocity.

2. SNA measures and analysis to capture of the network configuration, namely its morphology and composition. The following properties were analyzed (Sousa, 2008; 2012):

a) Network Size - indicates the number of network elements. It was measured using the number of nodes and the number of ties.

b) Connectivity - a network is connected when it is possible to find a path between all pairs of nodes. A network that has several components is not connected. One component is a set of nodes without 
links to the outside. When a network is composed of several components the ability of an actor to access network resources (including knowledge) is lower. In this paper we consider the number of components and the size of the largest component.

c) Density - captures the strength of the interconnection of the network. It is the ratio of the number of links present in the network and the total number of possible links. Much of the debate on the shape of the most favorable networks in the innovation process uses this indicator.

d) Strength of the ties - according to Granovetter (1982) the strength of ties can be analyzed through a combination of the amount of time, emotional intensity, intimacy and reciprocity that characterize the tie. As already mentioned, a tie is considered strong when it is reciprocal, that is, when both partners mention the partnership. The proportion of strong ties in total number of ties also gives an indication of the network cohesion.

e) Composition - the networks can be formed by various types of actor and we calculate the proportion of each type of in the total number of nodes. More specifically, we indicate the proportion of universities in each network.

f) Centrality - the analysis of centrality allows understanding the positioning of the different actors in the network. In this paper we considered two measures of centrality: i) degree centrality, which expresses the number of direct ties that an actor has with the other actors in the network, as a measure of activity; ii) betweeness centrality, which considers the number of times an actor lies between each pair of other organizations, enabling to assess whether an actor acts as broker facilitating the flow of information on the network. This measure captures situations in which actors have few contacts, but have a great importance in mediating the exchange and control of information circulating on the network.

\section{Analysis of Partnership Networks}

This section describes the results of the analysis of the firms' collaborative networks. As previously mentioned, here networks of different levels of specificity were considered to analysis: overall network of partnerships (broader includes all identified partnership), network of strategic partnerships (only includes partnerships classified as strategic) and network of Open Innovation practices (only includes the strategic partnerships which involve Open Innovation practices).

\section{Overall Network of Partnerships}

This network of partners involves 57 nodes (including the nine interviewed companies) and 55 ties (Figure 1). This relatively fragmented, especially if we take into account that all the interviewed companies belong to the same vertical of cloud computing). The network is made up of five distinct components, reflecting partnerships between interviewed companies or partner sharing between them is relatively rare. This fragmentation may hinder the diffusion of information and knowledge among the members of the association.

It is a network with a low density, since only $1.7 \%$ of the possible links are active (Table 1). This configuration is pointed out in the literature as being favorable for the generation of radical innovations, since it encompasses few redundant connections, promoting the access to novel ideas (McEvily \& Zaheer, 1999). Nevertheless, it may be unfavorable to the development of trust, which is considered necessary for the exploration and implementation of these innovations (Ahuja, 2000; Gulati, 1998). This idea is reinforced by the fact that strong ties are also relatively infrequent. In fact, only two partnerships are seen as reciprocal, both involving Firm 8.

Figure 1. Global Network of Partnerships

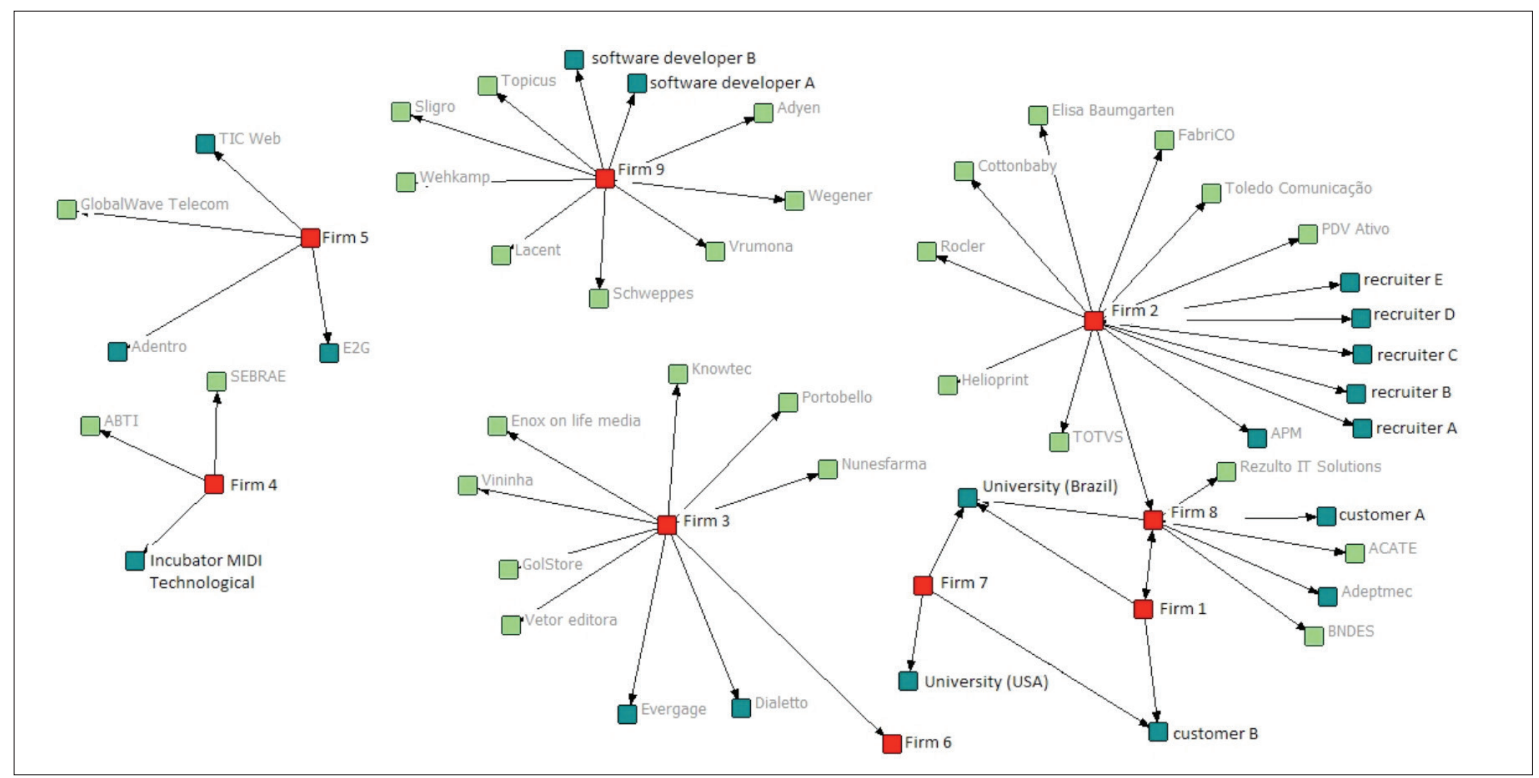

Source: Research Data preparation of authors

ISSN: 0718-2724. (http://jotmi.org)

Journal of Technology Management \& Innovation (c) Universidad Alberto Hurtado, Facultad de Economía y Negocios. 
Table 1. Information on the Global Network of Partnerships

\begin{tabular}{|l|c|}
\hline \multicolumn{1}{|c|}{ Indicator } & Value \\
\hline Number of nodes & 57 \\
\hline Number of ties & 53 \\
\hline Number of components & 5 \\
\hline Dimension of the largest component (nodes) & 26 \\
\hline Density & $1,7 \%$ \\
\hline \% Strong ties & $3,8 \%$ \\
\hline \% Universities in all of nodes & $3,5 \%$ \\
\hline
\end{tabular}

Source: Primary Data

\section{Network of Strategic Partnerships}

Strategic partnerships can be important strategies to be adopted in the context of disruptive innovations, such as cloud computing. Especially with the particularities and degree of novelty of the services using the infrastructure of this computational concept. In this way, the high investments and risks associated with emerging technologies reinforce the adoption of an open model in innovation management. In other words, given the complexity of the new computational model, the tendency to form strategic partnerships can be increasingly used. The complementarity of resources and knowledge among organizations involved in those partnerships, favors the success of innovation processes.

From the total 53 partnerships that were identified, the interviewed companies consider 26 as strategic. The network reflecting them is represented in Figure 2. This network, compared with the overall, exhibits a higher density, incidence of strong ties and presence of universities.

Figure 2. Network of Strategic Partnerships

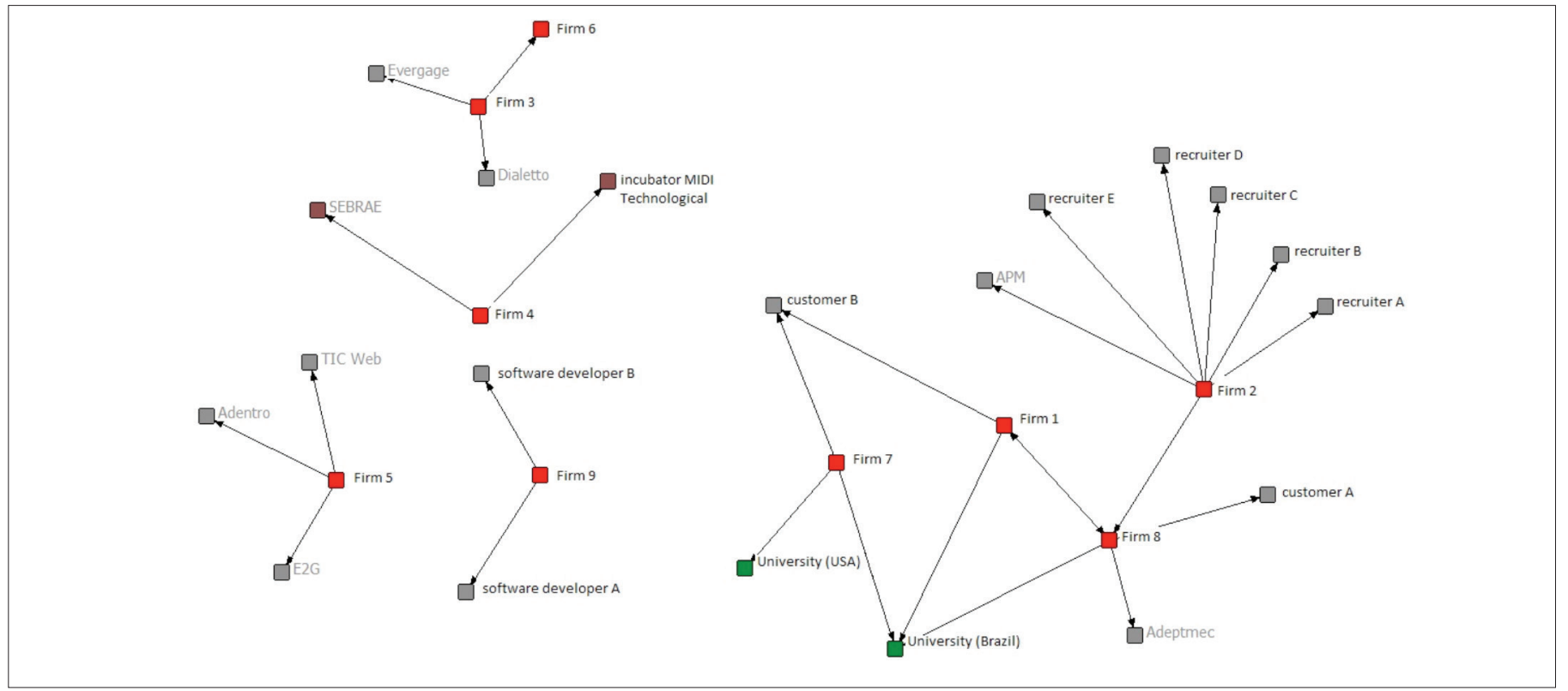

Source: Primary Data

Table 2. Information on Network of Strategic Partnerships

\begin{tabular}{|l|c|}
\hline Indicator & Value \\
\hline Number of nodes & 30 \\
\hline Number of ties & 26 \\
\hline Number of components & 5 \\
\hline Dimension of the largest component (nodes) & 16 \\
\hline Density & $3,0 \%$ \\
\hline \% Strong ties & $7,7 \%$ \\
\hline \% Universities in all of nodes & $6,7 \%$ \\
\hline
\end{tabular}

Source: Primary Data

Firm 2 has partnered with five human resources recruiting companies, a hardware supplier, complementing the offer of its product, and Firm 8 , in a partnership seen as reciprocal where there was clearly a mutual exchange of market expertise.
In the case of Firm 4, the strategic partnerships are actually with support institutions, more specifically with an incubator and a support SME organization. These alliances are very relevant for the early stage in which the Firm is. The active participation of its managers in events and courses offered by these institutions promotes the environment of networking and the identification of new business opportunities.

Firm 5 mentioned, as strategic partners, two communication agencies, with which it develops a supplier-customer relation. The data storage infrastructure provider, ('Adentro'), despite being a relatively recent partnership (at the time of the interview) is also already considered strategic for the company. Therefore, this firm only establishes strategic partnerships with suppliers, and there are no interactions with other companies in the same segment or universities. 
Firm 6 is only linked to Firm 3. This is an interesting situation, since firm 6 stated that it does not enter into partnerships and does not actively use networks of which it is a part. On the other hand, Firm 3 mentioned Firm 6, as one of its strategic partners. This situation makes evident the lack of understanding about the type of interaction between these firms. In the sense that Firm 6 considers the interaction with Firm 3 only a supplier-customer relationship, not considering it as a strategic partnership, therefore not having mentioned it in the interview and stating that it does not establishes Partnerships or adopts an Open Innovation management.

Firm 7 has established strategic partnerships with universities. Two cases are identified. The first is a Brazilian university, with whom a partnership was established and already finished. The dissolution was due to the fact that the outcomes did not match expectations. The firm acknowledges that there were failures in communication among that affected this outcome. The company then developed a new strategic partnership with a North American university within the scope of a particular project and with the clear goal of support its internationalization. Also, the visibility and prestige of the foreign partner were important motivating factors for the establishment of this relationship.
Firm 9 shows some particularities. The partnerships mentioned include software developers that are spin-offs of the company. Some self-employed professionals identified the opportunity and had a desire to start a new business, but could not begin it without support. Firm 9, recognizing the potential of the project, decided to participate in a joint venture and provided the infrastructure and support in the product development (expert knowledge).

\section{Network of strategic partnerships that involved open inno- vation practices}

From the 26 strategic partnerships mentioned during the interviews, only nine were identified as involving some practice characteristic of the open model. These practices were recognized thorough a content analysis of the interviews. Based on the theory of collaboration networks and on the Open Innovation literature, 11 practices were identified that correspond to the Open Innovation model among the strategic partnerships mentioned in the previous section.

Figure 3. Network of Strategic Partnerships involving Open Innovation Practices

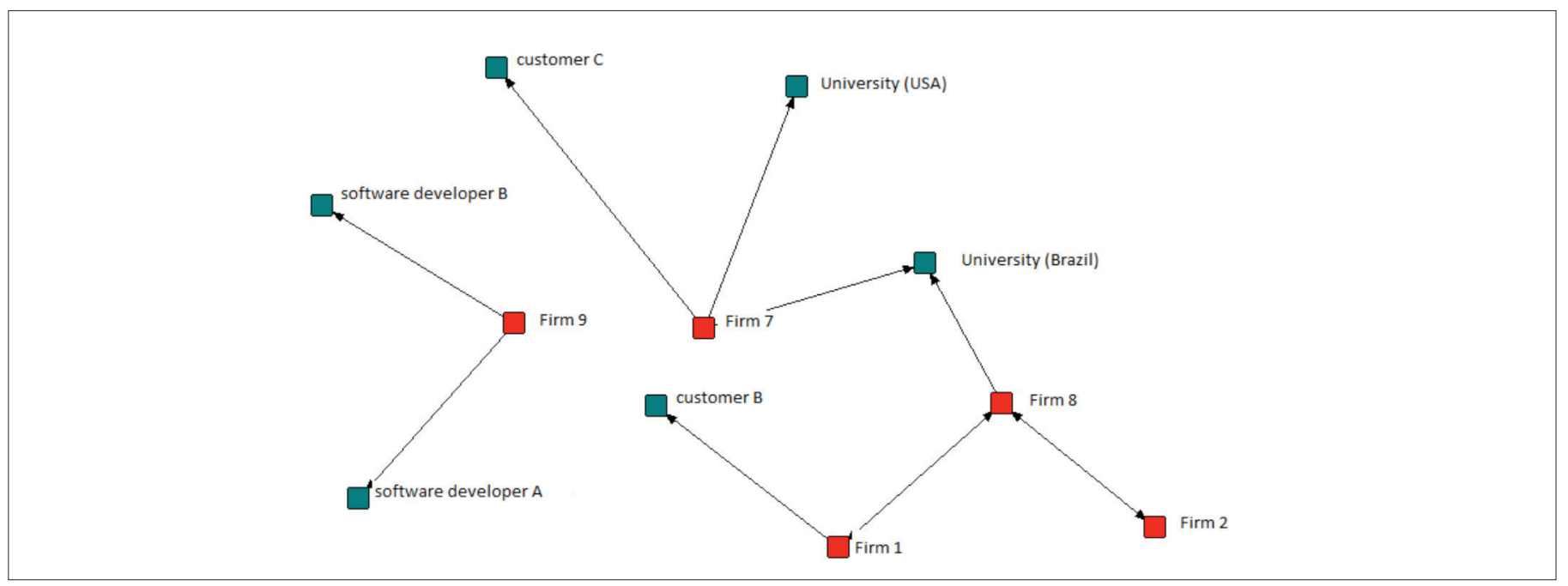

Source: Research Data preparation of authors

The Open Innovation practices present in the strategic partnerships are:

- Customer involvement: Firms 1 and 7 appointed partnerships with their clients. Two cases of Open Innovation practices were identified, because it is assumed that these interactions are involving the client in the development of new products. In the case of the Firm 1, the main motivation to involve the customer in the innovation process was its profound knowledge of the market that made possible to develop a technological solution closer to the market perceived needs. Although trust was already established between the two organizations, it was resolved to establish a legal contract to secure the rights and responsibilities of both parties. The strategic partnership resulted in new products for Firm 1.
- Outsourcing of R\&D: Two partnerships carried out by Firm 7 are considered open innovation practices in the scope of R\&D activities, both examples of interactions with universities. Together with an American university, Firm 7 began to make adaptations in some products with potential sales in international markets. The company reached this academic partner through a program to support Brazilian startups. The opportunity to internationalize the innovation network was a motivating aspect for Firm 7 in defining the partnership. Before the establishment of the alliance, there were face-to-face meetings in the US and in Brazil as a way to experience the environments from each other. The alliance was formalized through contract, stipulating the rights and responsibilities of the organizations. The alliance is still recent and therefore it is difficult to measure the outcomes attained. 
- Creation of new companies: Two practices of Open Innovation are identified that originated new companies with the support of Firm 9 and are considered strategic partnerships. The primary motivation of these partnerships was the opportunity recognized by professionals, who wanted to begin a new business. But they would not be able to develop their products without support, so they have searched for partners. Thus, Firm 9 did not promote the initiative of this alliance. The information about these new business opportunities reaches the company through an informal indication coming from employees, acquaintances or through networking. Afterwards, the company analyzes the potential of the project and when it considers it attractive, it designs the partnership, stipulating the tasks, the rights, and the responsibilities. A social contract is established to spread the company when business plans are at a more advanced level of development. It should be mentioned that Firm 9 does not invest on the new ventures, but rather provides infrastructure resources and expert knowledge. The two examples are still active partnerships, one beginning in 2009 and the other in 2011.

- Externalization of market competences: The cases of more substantial relationships occur between Firm 1 and Firm 8 and between Firm 2 and Firm 8, all participants in the cloud computing network of ACATE. The interaction between these organizations did not arise through ACATE, since the vertical of cloud computing did not yet exist. However, currently, the fact that they participate in this group is regarded as factor that strengthens the relation between them. The contacts between these companies were initiated by Firm 8, which uses a proactive partner identification strategy, in line with its growth strategy, in order to obtain the market knowledge needed to develop new products and, therefore, to increase the likelihood of successful in commercialization. At the same time, its partners (Firm 1 and Firm 2) actively participate in the product development process. It is therefore a practice of Open Innovation. The exploration of common markets was one of the main motivations, since both companies provide products and solutions for the same public. As such, some products have been integrated into each other's portfolio.

\section{Conclusions}

Collaborative partnerships can be essential strategies to be adopted in the context of complex innovations, as is the case of cloud computing. The high investments and risks associated with emerging technologies reinforce the idea defended by the adoption of the open model. In other words, in view of the complexity of the new computational model, the tendency to form partnerships and collaboration networks is of utmost significance. The complementarity of resources and knowledge among those involved favors the success of innovations. In this paper we tried to evaluate which collaborative practices are in fact practices characteristic of the Open Innovation model.

Brazil has some challenges in the infrastructure, which is an essential factor for the diffusion of cloud computing. Open Innovation, in this sense, can be a vital ally to reduce the effects of this lack of infrastructure, characteristic of emerging countries. Hence, companies can mitigate the deficiency of some competences through the interaction with other organizations.
However, when analyzing the indicators on the reality of innovation in Brazil, there is a low investment in R\&D by Brazilian companies. And this low investment is not being counterweighed by the use of collaboration networks and practices of Open Innovation. The Brazilian innovation scenario is still marked by the low degree of use of Open Innovation strategies (PINTEC, 2011).

After analyzing the results of this study, as well as analyzing the results and obtaining the conclusions, a set of hypotheses has been formulated, that may lead further research: Hypothesis 1 - The lack of systematization of the Innovation Management process can inhibit the adoption of the Open Innovation model, especially in the case of small and medium enterprises. Hypothesis 2 - A collaboration network strongly marked by the presence of composite networks may promote the 'trustees' factor. Hypothesis 3 - Companies tend to embrace the Open Innovation model in the development stage rather than the identification of ideas because the search for partners usually happens in a particular manner, to encounter an already identified need. Hypothesis 4 - The establishment of partnerships attenuates the uncertainty/risk associated with the adoption of Cloud Computing, favoring its diffusion.

\section{References}

Ahuja, G. (2000). Collaboration Networks, Structural Holes, and Innovation: A Longitudinal Study, Administrative Science Quarterly, 45: 425-455.

Blau, J. (2007). Philips Tears Down Eindhoven R\&D Fence. Research Technology Management 50(6): 9-10.

Chesbrough, H. (2003). Open Innovation: The New Imperative for Creating and Profiting from Technology. Boston: Harvard Business School Press.

Chesbrough, H. (2007). Why companies should have open business models. MIT Sloan Management Review, 48 (2): 22-28.

Chiaroni, D., Chiesa, V., Frattini, F. (2010). Unravelling the process from Closed to Open Innovation: evidence from mature, asset-intensive industries. R\&D Management, 40 (3): 222-245.

Cohen, W.M., levinthal, D.A. (1989). Innovation and learning: Two faces of R\&D. The Economic Journal, 99: 569-596.

Cohen, W.M., Levinthal, D.A. (1990). Absorptive capacity: a new perspective on learning and innovation. Administrative Science Quarterly, 35 (1): 128-152.

Dittrich, K., Duysters, G. (2007). Networking as a Means to Strategy Change: The Case of Open Innovation in Mobile Telephony. The Journal of Product Innovation Management, 24: 510- 521.

Enkel, E., Gassmann, O. (2007). Driving Open Innovation in the Front End: the IBM Case, the EURAM Conference, May 16-19, Paris. 
Gann, D. (2004). Book review - Open Innovation: The New Imperative for Creating and Profiting from Technology, Research Policy, 10(1): 122-123.

Gassmann, O., Enkel, E., Chesbrough, H. (2010). The future of open innovation. R\&D Management, 40 (3): 213-221.

Granovetter, M. (1982). The Strength of Weak Ties: A Network Theory Revisited. In P. Marsden \& N. Lin, Social Structure and Networks Analysis. Berverly Hills: Sage: 105-130.

Gulati, R. (1998) Alliances and networks, Strategic Management Journal, 19: 293-317.

Hemphill, T. (2005). Book review - Open innovation: The New Imperative for Creating and Profiting from Technology. Academy of Management Executive, 19: 164-165.

Laursen, K., Salter, A. (2006). Open for innovation: the role of openness in explaining innovation performance among U.K. manufacturing firms. Strategic Management Journal, 27: 131-150.

Lee, S., Park, G., Yoon, B., Park, J. (2010). Open innovation in SMEsan intermediated network model. Research Policy, 39(2): 290-300.

McEvily, B. and Zaheer, A. (1999) Bridging ties: a source of firm heterogeneity in competitive capabilities, Strategic Management Journal, 20: 1133-1156.

Napolitano, G. (1989). Industrial Research and Sources of Innovation. A Cross-Industry Analysis of the Italian Manufacturing Firms. Columbia University.

PINTEC Pesquisa Nacional de Inovação Tecnológica (2011). Retrieved from: http://www.ipea.gov.br/agencia/images/stories/PDFs/ nota_tecnica/131206_notatecnicadiset15.pdf.
Rothaermel, F.T. (2001). Incumbent's advantage through exploiting complementary assets via interfirm cooperation. Strategic Management Journal, 22 (6-7): 687-699.

Smith, P. (2004), Book review- Open innovation: The Open Innovation: The New Imperative for Creating and Profiting from Technology. Journal of Product Innovation Management, 21: 221-224.

Sousa, C. (2008). Redes Sociais e Empreendedorismo. Retrieved from: https://repositorio.iscte-iul.pt/bitstream/10071/3213/1/DINAMIA_WP_2008-68.pdf.

Sousa, C. (2012). Using social network analysis to study entrepreneurship: Methodological issues, In: SALAVISA, I., FONTES, M (eds). Social networks, Innovation and the Knowledge Economy. London and NY: Routledge.

Teece, D.J. (1986). Profiting from technological innovation: implications for integration collaboration, licensing and public policy. Research Policy, 15: 285-305.

Valk, T., Chappin, M.M.H., Gijsbers, G.W. (2011). Evaluating innovation networks in emerging technologies. Technological Forecasting \& Social Change, 78: 25-39.

Vanhaverbeke, W., Vermeersch, I., Zutter, S. (2012). Open Innovation in SMEs: How can small companies and start-ups benefit from open innovation strategies? Research Report. Retrieved from: https://sciencebusiness.net/eif/documents/Open-innovation-in-SMEs.pdf

Von Hippel, E. (1986). Lead Users: A Source of novel products concepts. Management Science, 32: 791-805.

Zeng, S.X., Xie, X.M., Tam, C.M. (2010). Relationship between cooperation networks and innovation performance of SMEs. Technovation, 30: 181-194. 
